\title{
CORRECTION
}

View Article Online

View Journal I View Issue

Check for updates

Cite this: New J. Chem., 2019, 43, 18394

DOI: 10.1039/c9nj90157d

rsc.li/njc

\section{Correction: Desymmetrization of disubstituted aromatic crown ethers via intramolecular Cannizzaro reactions}

\author{
Mason A. Rouser and Harry W. Gibson*
}

Correction for 'Desymmetrization of disubstituted aromatic crown ethers via intramolecular Cannizzaro reactions' by Mason A. Rouser et al., New J. Chem., 2019, 43, 16801-16805.

The authors would like to correct Fig. 1, as the peaks are labeled incorrectly in the published article. The label at $m / z 628.2979$ should read " $2 \mathbf{e}+\mathrm{NH}_{4}^{+}$", and the peak at $m / z 633.2533$ should be labeled " $2 \mathbf{e}+\mathrm{Na}^{+}$". The correct Fig. 1 is shown below.

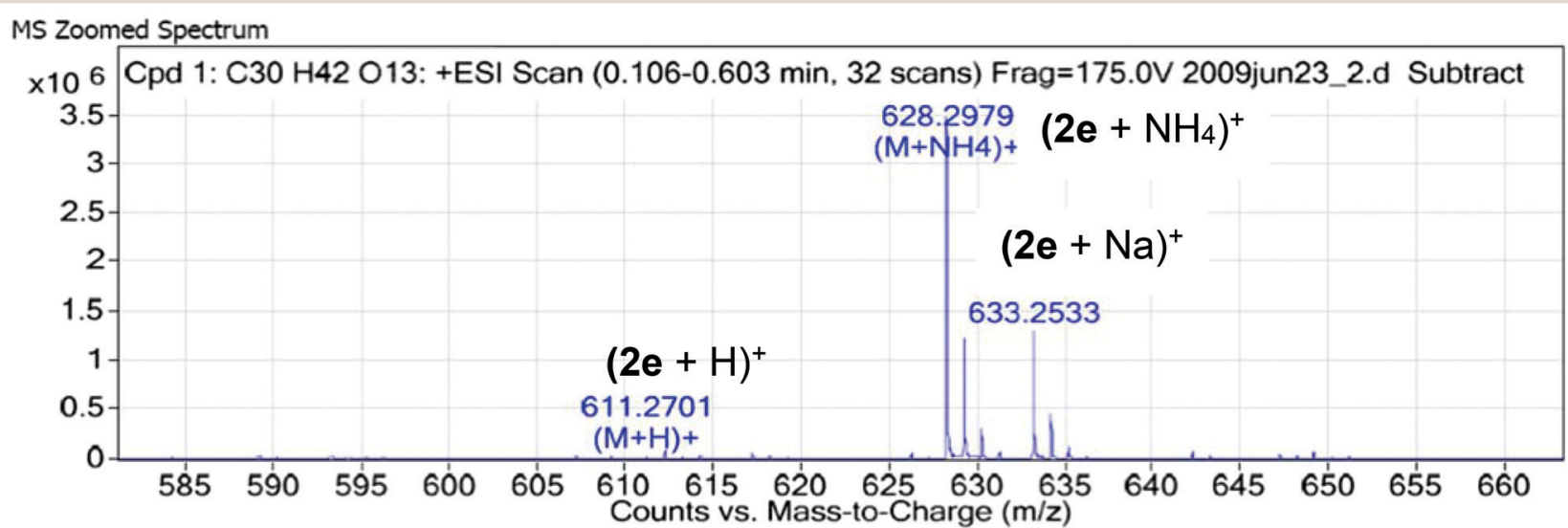

Fig. 1 ESI HR MS of DB30C10 acid-alcohol product $2 \mathbf{e}$ obtained using $\mathrm{Ba}(\mathrm{OH})_{2}$ as the base and templating agent in the intramolecular Cannizzaro reaction of dialdehyde $\mathbf{2 c}$. Note the absence of starting dialdehyde $\mathbf{2 c}\left[\mathrm{m} / \mathrm{z} 593.3(\mathrm{M}+\mathrm{H})^{+}\right]$, diol $\mathbf{2} \mathbf{b}\left[\mathrm{m} / \mathbf{z} 614.3\right.$ and $\left.619.3\left(\mathrm{M}+\mathrm{NH}_{4}\right)^{+}\right]$and diacid $\mathbf{2} \mathbf{d}[\mathrm{m} / \mathbf{z}$ $642.3(\mathrm{M}+\mathrm{Na})^{+}$], products that were formed when $\mathrm{NaOH}$ was used as the base.

The Royal Society of Chemistry apologises for these errors and any consequent inconvenience to authors and readers. 